\title{
UNIFICAÇÃO DE MOEDAS ENTRE BRASIL E ARGENTINA: UMA REFLEXÃO SOBRE SUA IMPLANTAÇÃO E POSSÍVEIS CONSEQUÊNCIAS
}

\section{ARTIGO ORIGINAL}

ALVES, Cláudio Marques ${ }^{1}$

MOLLICA, Rogerio ${ }^{2}$

ALVES, Cláudio Marques. MOLLICA, Rogerio. Unificação de moedas entre Brasil e Argentina: Uma reflexão sobre sua implantação e possíveis consequências. Revista Científica Multidisciplinar Núcleo do Conhecimento. Ano 05, Ed. 01, Vol. 05, pp. 75-92. Janeiro de 2020. ISSN: 2448-0959, Link de acesso: https://www.nucleodoconhecimento.com.br/lei/unificacao-de-moedas

\section{RESUMO}

No início de junho de 2019 o presidente do Brasil, Jair Bolsonaro, em visita à Argentina, trouxe à baila a possibilidade de ambos países criarem uma moeda única, concretizando assim um sonho acalentado há décadas, com vista a imprimir maior estabilidade econômica e estrutural entre os países signatários. Não obstante as boas intenções, a ideia (um assunto há anos adormecido) não encontrou coro dentro da comunidade economista brasileira: o próprio ministro da Economia, Paulo Guedes, que defende desde 1980 tal iniciativa mostrou-se receoso, porque embora sua

\footnotetext{
1 Mestrando em Direito pela Universidade de Marília. Pós-graduado em Direito Processual Civil pela Universidade Cândido Mendes. Mestrado financiado por Bolsa de Graduação/Pós-Graduação de iniciativa do Tribunal de Justiça do Estado de Goiás. ${ }^{2}$ Doutor e Mestre em Direito Processual Civil pela Universidade de São Paulo. Professor Doutor nos cursos de Mestrado e Doutorado na Universidade de Marilia Unimar. Membro fundador e Presidente do Ceapro - Centro de Estudos Avançados de Processo. Membro do Instituto Brasileiro de Direito Processual (IBDP).
} 
implantação pudesse trazer benefícios relevantes ao Brasil, não há condições de ser levada adiante no momento atual, devido à situação de fragilidade em que se encontram as duas economias. Cabe indagar então por que não prosseguir com tal desiderato, tendo em vista a discussão sobre o tema já ser antiga, vez que desde a década de 1980 já se trata do assunto. Longe de pretender esgotar o tema, o presente ensaio tem por escopo, a partir do método dedutivo e comparativo, através de pesquisas bibliográficas, em periódicos e sites da internet, ajudar o leitor a compreender as vantagens e desvantagens de uma iniciativa dessa natureza e os motivos que a obstaculizam.

Palavras-Chave: Relações Brasil-Argentina, Unificação Monetária, Moeda Única.

\section{INTRODUÇÃO}

A Constituição Federal de 1988 estabelece, em seu artigo 4º parágrafo único, que "a República Federativa do Brasil se rege nas suas relações internacionais, dentre outros princípios, pela busca de uma integração econômica, política, social e cultural dos povos da América Latina, visando à formação de uma comunidade latino-americana de nações".

Dentro dessa concepção e sabendo-se que apesar de promulgada no final da década de 1980, a atual Carta Magna é fruto de um longo e turbulento processo histórico, no qual restaram evidenciados o desejo e o dever de capitanear, como maior país do continente, o desenvolvimento econômico entre os países que o compõem, o que certamente motivou o legislador constituinte a inserir tal dispositivo no texto constitucional.

Nesse jaez, torna-se fácil entender o motivo de constar na agenda econômica de ambos países desde a década de 1980, o desejo de se estabelecer uma moeda comum, que poderia se estender aos demais países do Mercosul.

O assunto não causa, pois, estranheza, vez que desde sua formação como Estados independentes, os dois maiores países da América do Sul procuraram se inserir no 
concerto internacional a partir de uma atuação ativa semelhante, seja perante parceiros de alta envergadura, como Estados Unidos e Inglaterra, seja junto a países em desenvolvimento, como os da América Latina, Ásia e África.

A história das relações bilaterais Brasil-Argentina é recheada, porém, com episódios de parceria e rivalidade. Ora simpatizantes, ora antagonistas, é comum encontrar situações de distanciamento dessas duas nações, sobretudo no campo político, que por vezes repercutiu nas suas relações econômicas, embora com menor incidência nestas.

No final da gestão do general Julio Roca na Argentina, em outubro de 1904, as relações entre as duas nações eram de harmonia, tendo havido inclusive trocas de visitas entre seus presidentes. Campos Sales, por seu turno, legara um saldo de simpatia entre ambos, colocando fim a um período de frieza nas relações entre os dois países.

Focando apenas nos momentos de estabilidade e harmonia nas relações bilaterais, tem-se que na década de 1980, ainda sob o governo de ditaduras militares, Brasil e Argentina aproximavam-se diplomaticamente, tendo por objetivo debelar as crises financeiras pelas quais passavam. Houve várias visitas recíprocas, com o intuito de procurar meios e mecanismos para aliviar as tensões prementes em suas economias.

A ideia de uma moeda única surgiu, em verdade, durante os cinco encontros presidenciais ocorridos de julho de 1986 a novembro de 1988, quando então vinte e três protocolos e mais de quarenta Atas e Anexos foram assinados pelos plenipotenciários dos dois países. A ideia permaneceu inerte, sendo recolocada na mesa de discussões por ocasião da dolarização da economia argentina (1992-2002), repetida na primeira fase do Plano Real (1994-1999), e trazida novamente ao debate pelos ex-presidentes Lula e Cristina Kirchner em agosto de 2008, mesma época em que o economista Paulo Guedes, atualmente ministro da Fazenda, defendeu também em artigo para a revista Época a criação de uma moeda única entre os dois países, de tal forma que "o aprofundamento da integração econômica latino-americana em direção ao "peso-real", a moeda continental, é o passaporte para a modernização 
institucional de toda a região". Além disso, segundo Guedes, a criação de uma moeda única deflagraria um ciclo de reformas para assegurar a convergência de políticas tributárias, trabalhistas e previdenciárias.

Em que pesem os argumentos favoráveis ou contrários, as próximas páginas revelarão que vários aspectos devem ser melhorados e nivelados em todas as economias participantes, sob pena de se excessivamente beneficiar e onerar, simultaneamente, um ou outro país. $O$ assunto é bem mais complexo e intrincado do que se pensa, sendo talvez por isso que passados mais de trinta anos de idealização da proposta, a mesma sequer é cogitada para ser levada adiante pelas equipes econômicas dos governos que se sucederam.

\section{UNIÃO ECONÔMICA E MONETÁRIA: CARACTERÍSTICAS E ASPECTOS}

Antes de aprofundar no tema, cabe definir o que é uma unificação econômica e monetária, bem como suas características e as circunstâncias em que ela pode ocorrer.

Uma união econômica e monetária é uma situação envolvendo dois ou mais países que resolvem compartilhar políticas econômicas comuns e, em último nível, unificar suas moedas, de modo a dar maior competitividade ao seu câmbio, conferir maior poder de compra às suas moedas, reduzir os custos de transações financeiras e, entre outras finalidades, reduzir as desigualdades sociais internas. Segundo uma definição de PENA (2019):

União Política e Monetária: consiste em um mercado comum que ampliou ainda mais o seu nível de integração, que passa a alcançar também o campo monetário. Adota-se, então, uma moeda comum que substitui as moedas locais ou passa a valer comercialmente em todos os países-membros. Também é criado um Banco Central do bloco, que passa a adotar uma política econômica comum para todos os integrantes. O único exemplo de mercado comum e, ao mesmo tempo, 
de união política e monetária é a União Europeia, que é hoje considerada o mais importante bloco econômico da atualidade em razão do seu avançado nível de integração. Em muitos casos, essa integração alcança até mesmo as decisões políticas que eventualmente são tomadas em conjunto pelos países-membros.

Como se vê, é necessário criar-se um banco central para dirigir a política monetária comum e instalação de uma casa da moeda, podendo as cédulas serem impressas em ambos países. Conforme aponta INHASZ apud SHALDERS (2019), "embora a moeda comum possa ser confeccionada localmente nos dois países, a decisão sobre o quanto imprimir e quando passa a ser centralizada".

A criação, porém, de um Banco Central comum não é sinônimo de desmonte dos bancos centrais nacionais, haja vista que a política econômica a ser adotada será decidida previamente em conjunto pelos países interessados. Implica, por outro lado, em flexibilização de uma parcela da soberania, haja vista que a vontade de um Estado não poderá ser sobreposta à de outros, cabendo aí a articulação entre suas chefias visando a seguir um caminho comum.

A criação de um banco central comum requer a criação simultânea de uma autoridade monetária singular e com jurisdição sobre todos os parceiros. Deve ser dirigida por um conselho composto por membros de todos os países signatários, cujas decisões implicarão na aplicação dentro dos territórios nacionais que integrarem o bloco.

Por essas razões, pode-se notar que a unificação de moedas entre um ou mais países é um processo lento, complexo e burocrático, que requer adequações de todos os lados. Essas adequações passam, em proêmio, pelo equilíbrio das contas públicas, criação de uma zona de livre comércio entre os participantes, alinhamento de parâmetros macroeconômicos (como o nível de inflação e estabilização fiscal), nivelamento das taxas de juros, análises cambiais profundas e um estreito consenso nas políticas monetárias. Uma iniciativa desse tipo não pode ser excessivamente benéfica para um país e onerosa para outro; não pode permitir demasiada valorização de uma moeda em detrimento de outra. 
Grande parte das questões acima elencadas constituem há vários anos verdadeiros entraves nas políticas econômicas brasileira e argentina. Soma-se a isto o desequilíbrio de conta corrente do país, provocado pelo endividamento externo, destinado a financiar o consumo excessivo. Além deste, outros fatores devem ser levados em conta antes de se levar a termo a unificação monetária, quais sejam, a adequação da posição fiscal dos países, a relação custo-benefício ligada ao investimento ligado ao desequilíbrio externo e o pragmatismo nos aumentos de consumo, conforme analisam FRENKEL e GOLDSTEIN (1991):

Que atitude devem as autoridades tomar com relação aos desequilíbrios de conta corrente? Vários analistas - inclusive nós - consideram que tais desequilíbrios não são inerentemente bons ou maus; acham que devem ser avaliados caso a caso. Por exemplo, desequilíbrios resultantes de diferenças temporárias na distribuição etária da população dos países - que por sua vez geram diferenças nos padrões de poupança privada - geralmente não são graves; contudo, costumam ser graves os desequilíbrios que refletem endividamento externo insustentável, para financiar o consumo excessivo. Deveriam ser considerados, pelo menos, os seguintes fatores: se a posição fiscal é adequada (em termos do nível e da composição da despesa governamental, e também da estrutura dos impostos e dos empréstimos usados para financiar o orçamento); se o maior investimento ligado ao desequilíbrio externo poderá gerar um retorno superior ao custo do endividamento (inclusive externalidades); e se os aumentos de consumo ligados ao desequilíbrio são temporários e atendem às metas de equilibrar o consumo com o tempo.

No que tange à criação de uma zona de livre comércio, tal cenário ainda não existe no Mercosul. O que existe por aqui é um a união aduaneira, caracterizada pela existência de uma Tarifa Externa Comum (TEC), e uma zona de livre comércio restringida, dado à existência de salvaguardas impostas reciprocamente por seus 
participantes para a entrada de determinados produtos nos seus territórios. Segundo lição de WOLFFENBÜTTEL (2007),

A expressão "união aduaneira" simboliza uma associação de um grupo de países que se caracteriza por dois pontos: a adoção de uma tarifa externa comum e a livre circulação das mercadorias oriundas dos países associados. A implantação de uma Tarifa Externa Comum, conhecida como TEC, quer dizer que todos os países do grupo aplicarão a mesma taxação em relação à importação de bens de países fora do grupo. Essa TEC vai eliminar a concorrência entre os associados junto aos fornecedores. O Mercosul, formado por Brasil, Argentina, Paraguai e Uruguai, adotou a TEC em 1995. Isso implica, por exemplo, que o Brasil não pode decidir sozinho reduzir a taxação sobre determinado produto que ele compra da China em troca de algum benefício no mercado chinês. Para mudar a taxa, é preciso fazer um acordo com todos os quatro países-membros, que também reduzirão suas tarifas, ou seja, é preciso negociar em bloco. A segunda característica da união aduaneira é a formação de uma zona de livre circulação de mercadorias entre os diversos membros. No caso do Mercosul, essa segunda medida ainda não foi adotada. Os produtos argentinos, paraguaios e uruguaios têm salvaguardas para entrar no Brasil, e vice-versa. Por isso, o Mercosul é considerado uma união aduaneira imperfeita. Dois exemplos de uniões aduaneiras completas são a União Europeia e a Southern África Customs Union (Sacu, União Alfandegária do Sul da África), bloco liderado pela África do Sul.

No que concerne à política fiscal, vale ponderar que ela reflete o conjunto de medidas pelas quais o Governo arrecada receitas e realiza despesas de modo a cumprir três funções: a estabilização macroeconômica, a redistribuição da renda e a alocação de recursos. A função estabilizadora consiste na promoção do crescimento econômico sustentado, com baixo desemprego e estabilidade de preços. A função redistributiva visa assegurar a distribuição equitativa da renda. Por fim, a função alocativa consiste 
no fornecimento eficiente de bens e serviços públicos, compensando as falhas de mercado, segundo a definição tecida pela Secretaria do Tesouro Nacional do Brasil.

Dessa forma, é necessário que as políticas fiscais dos países participantes da união monetária estejam suficientemente disciplinadas e de acordo com as políticas monetárias dos mesmos, sob pena de não se conseguir a tão esperada estabilidade dos preços, o ajuste externo eficaz e a estabilidade do mercado cambial.

A disciplina fiscal pode ser melhor estimulada a partir da alocação de três mecanismos básicos, segundo lecionam FRENKEL e GOLDSTEIN (1991): regime cambial flexível com taxa de juros mais alta, somado à expansão fiscal e acabam por facilitar o financiamento do déficit fiscal; a redução de gastos governamentais dentro do mercado, seja ele interno ou externo, de modo a se evitar aumentar a tributação e consequentemente diminuir a arrecadação tributária; e a vigilância de grupos, como outro meio de estimular a disciplina fiscal, porquanto a observação de cada economia permitiria estabelecer para suas políticas fiscais regulamentações que fixassem individualmente tetos para o déficit fiscal de cada um, respeitando, claro, as diferenças entre cada país e impondo sanções àqueles que não cumprissem as metas e regulamentações fixadas.

Conforme dito anteriormente, a unificação monetária de dois ou mais países pode trazer estabilidade e prosperidade econômica para os envolvidos. Porém, o caminho para sua concretização é longo e complexo. No caso do Euro, o exemplo mais bem sucedido de que se tem notícia, levou mais de meio século de negociações e sua criação foi antecedida de um longo processo político, cujo viés econômico era o mote para colocar fim a uma ciranda de rivalidades que poderiam levar a novas situações de animosidade na Europa.

A seguir, uma breve explanação sobre a história do Euro e as causas que o fizeram (com avanços e recuos) lograr êxito no concerto europeu. 


\subsection{A UNIFICAÇÃO MONETÁRIA EUROPEIA: LIÇÕES PARA UMA POSSÍVEL MOEDA COMUM}

A criação de uma moeda comum na Europa não se justifica apenas por motivos econômicos, mas reveste-se, historicamente, de cunho político e humanitário. Prepondera aí o desejo de se colocar fim a uma história de guerras e conflitos que se sucederam, seja por demarcação de fronteiras dos Estados nacionais, seja pela expansão territorial e religiosa, ou ainda pela conquista de mercados, que ceifaram milhões de vidas, solaparam o crescimento econômico e a harmonia entre diversas nações do velho mundo, conduzindo-as a uma condição de atraso e dependência no decorrer dos séculos XIX e XX.

Após a Segunda Guerra Mundial e por ter sido palco das operações militares, o continente europeu encontrava-se praticamente todo devastado. A perspectiva de se evitar novos conflitos, estabilizar as relações entre as nações europeias e incrementar o crescimento econômico começou a ganhar força, concentrando esforços no sentido de unir-se o continente e implantar uma nova mentalidade coletiva nos povos, nascendo aí os famosos conceitos da "Paz Perpétua" e da "Construção da Europa". Segundo LESSA (2003, p. 19-21),

A ideia da união da Europa se confundiu durante muito tempo com a da própria organização do mundo, em uma assimilação que então se justificava pelo fato de que no Velho Continente se resumiam o mundo conhecido e o mundo útil, pelo menos desde o início do século XVII essas ideias se cruzaram e se alimentaram reciprocamente, dando origem a vasto e rico pensamento filosófico e político sobre as possibilidades que a paz na Europa traria para o mundo. Os diferentes e sucessivos projetos de paz perpétua que são publicados a partir de então traduzem a existência desse pensamento, que identifica o fim das guerras e das tensões na Europa e, portanto, a abertura de uma era de prosperidade, com a necessidade de se estabelecer a cooperação efetiva entre as grandes potências do continente. 
No dia 25 de março de 1957 foi assinado em Roma, na Itália, o tratado que criou a Comunidade Econômica Europeia (CEE), inaugurando aí um novo bloco econômico cuja finalidade precípua era implementar uma nova mentalidade nos povos europeus, através da integração econômica, de modo a se prevenir novos conflitos bélicos, que assolaram a região durante a primeira metade do século XIX.

Após sua ratificação pelos Estados-membros, sua entrada em vigor se daria no dia 1ํㅡㄴ de janeiro do ano seguinte, constituindo aí o início de uma Europa integrada política e economicamente. O cenário de mercado comum foi o propulsor para a aceitação quase unânime de uma moeda comum, visando à harmonia das populações envolvidas, conforme leciona LESSA (2003, p. 50):

O tratado que instituiu a Comunidade Econômica Europeia (CEE), marco fundamental do processo de construção da Europa, tinha por objetivo precípuo estabelecer um mercado comum entre os parceiros, promovendo um desenvolvimento harmonioso das atividades econômicas, a sua expansão contínua e equilibrada, a melhora acelerada do nível de vida das suas populações e, evidentemente, de acordo com a letra do tratado, "relações mais estreitas entre os Estados europeus". O mercado comum que vinha de ser criado estabelecia uma união aduaneira, que punha fim aos direitos alfandegários e a outras formas de restrições ao comércio entre os membros, erigindo uma tarifa externa comum - medidas que entrariam em vigor progressivamente, ao longo de um período de transição de doze anos.

Dentro da ideia de integração do continente em uma comunidade pacífica e harmoniosa de nações, tomou força a propositura de criação de uma moeda única, o que em tese traria equilíbrio financeiro aos países do bloco. Entretanto, fazia-se necessário a criação de uma área em que fosse possível a livre circulação de bens, de pessoas, serviços e capitais, o que pressupunha a integração dos países em um mercado comum, que seria, no final, um o corredor por onde circularia uma eventual moeda única. Na lição de PECEQUILO (2014, p. 54), 
No que se refere ao Mercado Comum, o mesmo é implementado, englobando o que é definido pela União Europeia como liberdade de circulação de pessoas, bens, serviços e capitais. O Mercado Comum é o último estágio da integração econômica europeia que havia sido iniciada em 1957, já tendo como objetivo a construção deste espaço único. Desde o Tratado de Roma, até chegar-se ao Mercado Comum, o bloco atravessou as fases da área comercial, união aduaneira e mercado único, ao longo das últimas décadas.

Estabelecida a zona de livre comércio pela constituição do que passou a ser o Mercado Comum Europeu, após décadas de tratativas e acordos, finalmente concluiuse pela unificação monetária e econômica. Entretanto, muitos ajustes deveriam ser feitos nas economias dos participantes até se começar a distribuir fisicamente as novas cédulas. Segundo PECEQUILO (2014, p. 57), estes ajustes compreendiam, entre outras medidas, a estabilização dos preços pela limitação da taxa de inflação a 1,5\%; a eliminação de barreiras fiscais, a imposição de taxas de câmbio dentro da margem de flutuação autorizada durante os dois anos anteriores; a limitação das taxas de juros a longo prazo em 2,00\% em relação à média das taxas dos três Estados com as taxas mais baixas; os déficits públicos nacionais não poderiam ultrapassar 3,00\% do PIB. Deveria ocorrer também a criação do Conselho Monetário Europeu e do Banco Central Europeu, que estabeleceriam, a partir do consenso entre os parceiros, a política monetária europeia.

Antes, porém, criou-se o Sistema Monetário Europeu (SME), que entrou em vigor aos 13 de março de 1979, em coexistência com o sistema monetário internacional, referenciado em dólar norte-americano. Não que o dólar tivesse parado de circular dentro da Europa, mas era preciso criar uma moeda, vigiada por outro sistema monetário, capaz de resistir a crises de desvalorização que refletiam no enfraquecimento da moeda, na descrença da estabilidade das taxas de câmbio e na restrição à circulação de bens e capitais dentro do bloco, conforme aponta ainda LESSA (2003, p. 86): 
A entrada em vigor do Sistema Monetário Europeu (SME), no dia 13 de março daquele difícil ano de 1979, também mostrou ser um marco significativo na construção da Europa, mesmo tendo em conta que o sistema monetário internacional continuasse, em grande parte, dominado pelo dólar norte-americano e particularmente influenciado pela crise econômica característica dos anos 70. A decisão de cria-lo partia da percepção de que a sucessão de crises, além do efeito negativo na estabilidade das taxas de crescimento econômico, acabaram também com a crença na estabilidade das taxas de câmbio, marcada pelo enfraquecimento gradual do dólar, caracterizado por suas repetidas desvalorizações a partir de 1971, e pelas alterações bruscas e unilaterais na equivalência do franco francês e do marco alemão (a partir de 1969). Acresce que a alta instabilidade cambial prejudicava não apenas a concertação de políticas macroeconômicas entre os Estados-membros, mas tornava particularmente difícil a circulação de bens e capitais no espaço europeu integrado.

Uma das instituições mais importantes para o bom funcionamento da unificação monetária na zona do Euro foi a criação do Banco Central Europeu, o qual, conforme PECEQUILO (2014, P. 57), ascendeu como "principal interlocutor, formulador e tomador de decisão no campo da política monetária" na terceira etapa do período de transição do Sistema Monetário Europeu para o Euro, que foi de 1ํ de janeiro de 1999 a $1^{\circ}$ de janeiro de 2002. Seu objetivo principal nessa cadeia evolutiva era o de assegurar a estabilidade dos preços na Zona do Euro e o desenvolvimento econômico geral da comunidade econômica comum.

Atualmente, 19 dos 28 países da União Europeia utilizam o Euro como moeda, abrangendo uma população de quase 340 milhões de pessoas, sendo o exemplo mais visível de um processo de unificação monetária. Os fatores históricos que culminaram no desejo e na concretização de uma moeda única, como visto no concerto europeu não encontram, porém, similaridade na América do Sul. 
Abrindo aqui um parêntese, é oportuno explicar sobre um importante mecanismo estudado em filosofia, do qual pode-se notar sua utilização de forma eficaz no encaminhamento da questão do Euro: um discurso de viés econômicoconstitucionalista, calcado na disseminação da ideia de integração do continente em um mercado comum e criação de moeda única na Europa como o meio mais adequado e eficaz para se estabelecer a paz perpétua no continente e cessar o derramamento de sangue em guerras.

Tal enredo amolda-se a um campo semântico concebido dentro da lógica de "biopoder", conceito este tecido pelo filósofo francês Michel Foucault para definir as relações de poder que envolvem dois ou mais atores em um contexto de relações de poder, visando à persecução de um dado objetivo ou interesse previamente estabelecido. Ele leva em conta, pois, induzir os cidadãos a praticarem determinada conduta ou aceitarem certos padrões preestabelecidos como certos e necessários, com vista a se atingir um determinado fim ou objetivo, normalmente impostos pelo Estado, consoante lição magistral de SERVA e DIAS (2016, p. 426-427):

(...) Essa tarefa tem ganhado importância pois prevalece atualmente a adoção de dispositivos de segurança para fazer com que as pessoas adotem esta ou aquela postura, em especial em face do surgimento e desenvolvimento do que se convencionou chamar de biopoder ou biopolítica que, segundo Foucault, consiste na adoção de mecanismos de controle que, incidindo sobre o conjunto da população, induzem para que ela adote esta ou aquela postura, tudo para atingir objetivos previamente definidos.

A partir então de uma massiva política de conscientização ou de imposição doutrinária, os governos dos países que aceitaram inicialmente a ideia incutiram nos seus cidadãos a ideologia de que a integração econômica e monetária regional se fazia imprescindível e urgente, utilizando aí uma estratégia que Michel Foucault denomina como "biopolítica", a qual é, senão, o conjunto de biopoderes destinados a fazer com o que as pessoas adotem práticas ou padrões de conduta. Nessa ótica, é pertinente e apropriada a ponderação de SERVA e DIAS (2016, p. 429): 
(...) É certo que atualmente tem prevalecido a primeira posição, com a adoção da biopolítica como um conjunto de biopoderes que são exercidos sobre as pessoas com o fim de convencê-las a adotarem esta ou aquela prática social, sem a preocupação com a emancipação da sociedade ou o desenvolvimento das potencialidades das pessoas. A título de exemplo, as pessoas são convencidas a comprarem determinado produto e trocá-lo assim que uma nova versão é lançada, como se a propriedade de tal bem fosse a única forma de garantir a satisfação pessoal. (...) Assim, deve-se abandonar o conceito de biopoder, que se caracteriza por seu caráter regulador, e adotar a biopolítica, que se destaca por sua proposta emancipadora, fazendo com que os seres humanos que compõem a população deixem de ser considerados os meios para a obtenção dos resultados esperados e se tornem protagonistas de um processo de emancipação.

Como se verá adiante, não há nesta parte do globo, à exceção de um ou outro episódio de tensão ou conflito armado, algo de relevo como os cenários de guerras mundiais pelos quais passou a Europa (desembocando prioritariamente na busca incessante pela paz entre as nações) que possam fundamentar, nessa esteira, uma biopolítica com matiz ideológico e comportamental nas populações envolvidas, destinada à implantação de uma moeda comum.

\section{RELAÇÕES BRASIL-ARGENTINA - ASPECTOS HISTÓRICOS}

Por ser o país de maior extensão territorial e com maior fluxo de capitais no continente, o Brasil acaba assumindo o papel de referência e líder em termos de política externa perante seus vizinhos. Sem a pretensão de exercer hegemonia de poder na região, o país consegue se manter atento às questões de vizinhança em virtude da estabilidade econômica e política que alçou na década de 1990. Conforme ensina PECEQUILO e CARMO (2015, p. 5-6):

Como país mais poderoso da América do Sul, o Brasil teria a desempenhar na região papel similar ao que França e Alemanha tiveram 
na integração europeia como "motor" político-econômico-estratégico do processo. Iniciado em sua fase atual nos anos 1990, este papel teria chegado ao seu amadurecimento no século XXI, beneficiando-se da recuperação e estabilidade política e econômica do país, que permitiu maior atenção aos seus vizinhos.

Ainda de acordo com os autores, essa atenção faz parte do viés ideológico adotado pela Constituição Federal de 1988, de que o país deve-se pautar nas suas relações internacionais por uma postura pacífica, não confrontacionista, calcada no princípio da autodeterminação dos povos, pela autodeterminação dos povos, na nãointervenção, na solução pacífica de controvérsias, bem como reger-se dentro dos princípios da cordialidade, da cooperação e do multilateralismo como forma de legitimar suas proposituras nos foros internacionais, conforme aponta.

Nessa seara, as relações com a Argentina se processam de forma mais intensa e contínua, por se tratar do segundo maior país do continente sul-americano e, ao mesmo tempo, o maior mercado consumidor de bens industrializados brasileiros, como automóveis, veículos de carga, peças para implementos agrícolas e produtos da chamada "linha branca" (geladeiras, fogões, e outros eletrodomésticos), ao passo que o Brasil também importa da república platina veículos, defensivos agrícolas e commodities vegetais (trigo, milho, arroz, azeitonas, etc.).

Durante muitas décadas as relações entre esses dois imponentes vizinhos no Cone Sul foram permeadas por sucessivos períodos de distensão e aproximação. Contudo, no final dos regimes militares, que caracterizaram seus governos inicia-se na década de 1980, uma nova realidade nas suas relações, fruto de uma nova postura política, que foi implementada.

Advinda de governos civis, que puseram termo às ditaduras, uma nova aspiração foi colocada na ordem do dia das duas nações-irmãs, através de uma série de tratados assinados a partir de julho de 1986: o desejo de crescer economicamente, de se desenvolver tecnologicamente e firmarem sua voz e seu espaço no concerto internacional, conforme lição de SEITENFUS (1989): 
A assinatura destes acordos torna-se possível em razão da evolução política interna que conhecem os dois países nestes últimos quatro anos. Com efeito, e esta é uma de suas principais características, os acordos respondem a uma vontade política dos dois governos. O regime civil instalado em recente data nos dois países, após um longo período de militarismo, ressente-se da necessidade de fortalecer-se no âmbito internacional. Ao mesmo tempo, a tentativa de superação das rivalidades históricas entre os dois países faz com que a iniciativa tenha um significado especial, uma vez que se trata de uma ação do poder civil e democrático, contrariando a visão militarista predominante até então. Independentemente dos fatores políticos que motivam a conclusão dos Protocolos, devemos reconhecer que as decisões tomadas possuem um caráter de praticidade pouco comum nos processos integracionistas latino-americanos. A ideia central sobre a qual repousa o acordo é a de buscar conjuntamente um crescimento econômico dos dois países - a expressão "crescer juntos" é consagrada nos Protocolos. Uma outra razão pouco enfatizada até o presente é a busca pelos dois países de uma modernização econômica. $O$ processo de integração representa uma abertura maior das economias, com um aumento de competição nos dois mercados e por via de consequência uma rápida atualização tecnológica e uma maior eficiência. Isto provocaria a abolição de redutos privilegiados que se mantêm graças à concessão de subsídios públicos.

\section{ECONOMIAS BRASILEIRA E ARGENTINA: CENÁRIOS ATUAIS}

No que tange à atual situação econômica desses dois gigantes do Cone Sul, é fácil perceber o quanto precisam se ajustar para começar a tratar do delicado assunto de unificação monetária.

Atualmente as situações econômicas do Brasil e da Argentina não são das melhores, pois os dados relacionados à criação de empregos e ao PIB de 2018 demonstram que a economia brasileira está se recuperando em ritmo lento desde a crise de 2014, porém com um percentual modesto de criação de empregos e um aumento expressivo 
na taxa de desemprego. No primeiro trimestre de 2019 essa taxa atingiu 12,7\%, segundo a Pesquisa Nacional por Amostra de Domicílios, promovida pelo Instituto Brasileiro de Geografia e Estatística (IBGE), conforme relata o jornal Valor Econômico. Ou seja, é uma massa de desempregados que chega ao patamar de 13,39 milhões de pessoas. Na Argentina, no mesmo período, o número de trabalhadores sem emprego chegou ao percentual de $10,1 \%$ da população, totalizando 1,96 milhão de pessoas involuntariamente ociosas, conforme dados divulgados pelo Instituto Nacional de Estadística y Censos de Argentina (Indec). Esse número estava em torno de $9,1 \%$ em 2018 , representando quase $4,5 \%$ da população do país.

O endividamento externo brasileiro, em abril de 2019 , encontrava-se na cifra de $R \$$ 3,878 trilhões, ao passo que na república platina, o valor da dívida pública externa passa dos US\$ 360 bilhões. Para economistas argentinos, esse valor já supera 100\% do Produto Interno Bruto do país e revela-se, infelizmente, uma dívida impagável. Com isso, ou o país vizinho quita sua dívida ou aumenta o índice de pobreza e miséria no país, que atualmente passa dos 38\% da população portenha, o que pode ser reflexo da crescente desvalorização do peso em relação ao dólar: um dólar corresponde a 45 pesos, atualmente.

O desequilíbrio entre as duas moedas é tamanho que diminui cada vez mais o poder de compra da renda do argentino. Segundo IGLESIAS e MILLAN (2019), "em recessão por quase dois anos, a Argentina sofreu com uma desvalorização de $50 \%$ do peso em 2018. A Economia brasileira tem crescido pouco mais de $1 \%$ ao ano desde que saiu de sua pior recessão em 2017".

Quanto à inflação, o Banco Central do Brasil aponta para uma alta nesse ano de 2019, podendo o índice chegar a 4,1\%, conforme o Relatório Trimestral de Inflação de março do mesmo ano, publicado pelo jornal Valor Econômico. De outra banda, a economia argentina enfrenta uma escalada inflacionária que atingiu, em abril de 2019, o pico de $55,8 \%$, conforme dados divulgados pelo Indec, em matéria também publicada pelo referido jornal. 
Além disso, no que tange às taxas de juro determinadas pelos bancos centrais, o Banco Central da Argentina impôs uma taxa de 73,9\% ao ano no mês de abril de 2019, a maior taxa já registrada naquele país. Enquanto isso, no Brasil, o Banco Central determinou, através do Comitê de Política Monetária e Econômica, que a mesma fosse delimitada aos $6,5 \%$ ao ano no mesmo período, tendo em vista a piora no cenário econômico interno.

Tendo em vista os cenários acima citados, depreende-se que embora também esteja passando por um momento de recuperação em sua economia, o Brasil ainda está com uma situação mais confortável do que o país vizinho, em termos percentuais e comparativos, uma situação que aponta para o fato de que a possibilidade de uma unificação monetária e econômica possa se revelar mais favorável à economia argentina do que à brasileira, colocando em xeque, no médio prazo, o pragmatismo da política externa brasileira.

\section{POSSÍVEIS CONSEQUÊNCIAS DE UMA UNIFICAÇÃO MONETÁRIA ARGENTINO-BRASILEIRA}

$\mathrm{Na}$ lição do economista clássico David Ricardo, em sua Teoria das Vantagens Comparativas, os países devem tornar-se especialistas na produção dos bens em que são melhores e possuem maior competência técnica e exportá-los para os países cuja produção desses mesmos bens é escassa ou carente. Da mesma forma, devem importar dos outros aqueles bens que não conseguem ou não podem produzir, tornando assim o comércio vantajoso para ambos os lados.

Trazendo tal conceito ao caso em análise, dados do Ministério da Economia brasileiro indicam que o comércio bilateral entre Brasil e Argentina rendeu, US $\$ 26$ bilhões no ano de 2018, mesmo tendo havido uma queda de 3,9\% em relação a 2017, o que ainda coloca a nação platina no patamar de terceiro país com maior fluxo de comércio com o Brasil. Uma eventual unificação monetária e econômica poderia, em decorrência da redução de impostos sobre operações financeiras, incrementar mais ainda esse número. 
Segundo PFEIFER apud SANT'ANA (2019), a unificação de moedas entre Brasil e Argentina proporcionaria em um primeiro momento vantagens para ambos países, como por exemplo, a criação de uma moeda forte e o estabelecimento de metas e critérios para o equilíbrio das suas contas públicas. Isso os obrigaria a promoverem reformas e ajustes fiscais (sobretudo a flexibilização da legislação trabalhista, revisão da política tributária e reforma no sistema previdenciário), medidas essas normalmente impopulares.

Ademais, segundo aponta o economista, a criação de uma moeda comum poderia levar a uma série de benefícios experimentáveis dos dois lados como por exemplo: a) criação de um Banco Central independente e imune às preferências flutuantes dos presidentes das repúblicas, dado que é necessário a instituição de uma autoridade monetária com poder para determinar as políticas econômicas e fiscais a serem adotadas pelos interessados; b) uma maior integração nacional dos países parceiros, tendo em vista o maior fluxo de capitais derivados de um comércio mais facilitado pela queda de impostos cambiais; c) diminuição dos riscos monetários e de vulnerabilidades fiscais, dentre outras vantagens. Seria possível ainda, segundo o especialista, adiantar o processo de crescimento econômico na região, bem como fluir melhor o comércio com outros países, em virtude de se criar ali um espaço econômico, livre e atuante.

Por outro lado, o economista ressalta serem visíveis as desvantagens advindas de um processo dessa envergadura, além de sérios riscos a que ambos países ficariam expostos.

Uma iniciativa desse porte exigiria, de modo geral, um alinhamento extremamente compatível entre as políticas públicas a serem adotadas pelos participantes dessa união monetária, algo nunca antes visto em toda a história da América Latina. Dentre esses entraves encontram-se ainda a perda de autonomia do país frente à formulação de sua política econômica, bem como acarretaria na flexibilização de parcela de sua soberania, no risco de contágio inflacionário e de desvalorização cambial, conforme analisa: 
Mas há também desvantagens e, em especial, riscos atrelados a esse processo. A principal é a perda de autonomia do país, já que teria de seguir as decisões monetárias e fiscais de acordo com o estabelecido pelo Banco Central da região. Já na área de riscos, haveria de ter um alinhamento nunca antes visto na América Latina entre os governos dos países que vierem a adotar essa moeda única, pois o fracasso de uma moeda única (ainda não visto no mundo) tende a ser mais devastador do que de uma moeda nacional. Outro risco é algum país do acordo entrar em crise financeira, obrigando os demais a arcar com os custos dessa crise, caso que já aconteceu na União Europeia, com a colapso da Grécia.

Quando se fala de unificação monetária, a comparação entre as realidades europeia e sul americana nesse sentido é quase impraticável, porquanto tratarem-se de contextos e cenários muito diferentes, salvo os períodos de crise financeira e instabilidade cambial pelos quais ambos amiúde atravessam. A Europa, por exemplo, levou mais de 30 anos para consolidar o processo de passagem de moedas locais para uma moeda única. Em que pese todo o sucesso de integração europeia e os sucessivos ajustes em suas economias, esse processo ainda não terminou, conforme pondera NÓBREGA (2019):

Como se vê, o euro é fruto de um processo longo, ainda inconcluso, que surgiu depois de mais de trinta anos de profunda e bem-sucedida integração econômica, que compreendeu a instituição de um sistema comum de tributação do consumo, o Imposto sobre o Valor Agregado, o IVA europeu. Brasil e Argentina sequer exibem a condição inicial para pensar em uma moeda única, o equilíbrio macroeconômico. Ambos estão em crise fiscal e a Argentina voltou a lidar com grave problema inflacionário. A ideia da moeda única não passa, pois, de um delírio.

Destarte, "só é possível ter moeda única quando houver convergência macroeconômica entre os dois países" (PFEIFER, 2019) e, corroborando tal assertiva, o que a história mostra é um cenário de constante indisciplina macroeconômica em 
ambos os lados. O simples fato de serem vizinhos, de ostentarem uma união aduaneira (ainda que imperfeita), movimentarem mais de 50\% do PIB da América do Sul e serem dirigidos atualmente por governos assemelhados em vários matizes durante as gestões Macri na República Platina e Bolsonaro no Brasil, não implica, necessariamente, que uma unificação monetária e econômica seria algo crível e tangível, pelo menos nos próximos 10 anos.

Mais ainda, se uma iniciativa desse porte fosse implantada abruptamente, sobretudo motivada por ambições políticas de grupos ou elites dominantes, desatrelada de uma rigorosa mudança estrutural e comportamental nas populações de ambos países, as consequências poderiam ser, com certeza, catastróficas.

\section{CONCLUSÃO}

A criação de uma moeda única no cenário do Mercosul ou abrangendo, em um primeiro momento, apenas Brasil e Argentina poderia, sim, ser a aurora de um crescimento econômico sem precedentes na região, como visto nas análises mencionadas ao longo do texto. A unificação monetária das duas economias proporcionaria maior troca de bens e serviços entre os países a partir do recrudescimento no fluxo de capitais, o que em princípio fomentaria a redução de desigualdades sociais e uma melhor distribuição de renda.

Contudo, há que se ponderar sobre a viabilidade de uma iniciativa desse modelo, vez que a mudança na economia perpassa, em um primeiro momento, pela mudança gradual de mentalidade nas populações envolvidas (como a inversão da cultura de propensão ao consumo para a propensão à poupança, por exemplo) o que refletiria certamente nas políticas públicas a serem implementadas para se chegar a esse estágio de evolução.

Devido à falta de conhecimento (ou interesse mesmo) de grande parcela das respectivas populações pelas questões mais prementes de políticas econômica e fiscal, as decisões mais importantes nesses campos ficam quase exclusivamente ao crivo de gestores públicos (algumas vezes bem-intencionados, mas mal informados). 
O que se tem em conta, por decorrência disso, é um desalinhamento de políticas econômicas, monetárias, fiscais e sociais em ambos países, historicamente recheadas de poucos avanços e muitos desacertos, frutos de um cálculo estratégico equivocado.

Dessa forma, uma biopolítica eficaz, aliada a políticas econômicas restritivas, que fossem capazes de fazer os governos diminuírem seus gastos, dependerem menos de financiamentos externos, induzirem a maior parte das populações envolvidas a conterem sua propensão ao consumo e desenvolver uma maior propensão à poupança, além de incentivar a indústria nascente, faria certamente com que o volume de liquidez do país crescesse a níveis que permitissem uma maior competitividade dos dois países nas relações com o resto do mundo. Com isso, o fortalecimento de suas moedas e economias seria algo mais crível, podendo-se então voltar a falar em unificação monetária e econômica.

Com base nas análises suscitadas ao longo do texto, comparar os cenários econômicos, políticos e sociais do Brasil e da Argentina ao europeu (presentes ou pretéritos), para a implantação de uma moeda única é tarefa absolutamente despicienda, não se podendo inclusive inferir o menor grau de compatibilidade entre eles. O Euro tem uma história e motivos próprios que levaram à sua criação, os quais transcendem, como já dito, o campo meramente econômico. É, pois, algo eminentemente intangível e irrealizável no contexto atual das economias do Cone Sul.

\section{REFERÊNCIAS}

BANCO CENTRAL DO BRASIL. Relatório de Inflação. V. 21, n. 1, Março 2019, disponível em: <https://www.bcb.gov.br/content/publicacoes/ri/201903/ri201903p.pdf>. Acesso em: 17 jul. 2019.

BRASIL. Constituição da República Federativa do Brasil. Planalto, Brasília, DF, 1988, disponível em <http://www.planalto.gov.br/ccivil_03/constituicao.htm>. Acesso em: 17 jul. 2019. 
BUENO, Clodoaldo. Política Externa da Primeira República: os anos de apogeu - de 1902 a 1918. São Paulo: Paz e Terra, 2003.

COLOMBO, Sylvia. PIB cai e desemprego cresce na Argentina. Folha de S. Paulo, 19.junho.2019, disponível em: <https://www1.folha.uol.com.br/mercado/2019/06/ desemprego-na-argentina-chega-a-101-no-primeiro-trimestre.shtml>. Acesso em: 17 jul. 2019.

FRENKEL, Jacob A. GOLDSTEIN, Morris. A incipiente unificação econômica e monetária da Europa. Revista Finanças \& Desenvolvimento, março 1991, p. 2-5, disponível em: <http://bibliotecadigital.fgv.br/ojs/index.php/fdesenvolvimento/article/viewFile/64891 /62786>. Acesso em: 17 jul. 2019.

GRANER, Fábio. VERSIANI, Isabel. BC vê inflação de 4,1\% em 2019 e 4\% em 2020. Valor Econômico, 28/03/2019, disponível em: <https://www.valor.com.br/brasil/6186129/bc-ve-inflacao-de-41-em-2019-e-de-4-em2020>. Acesso em: 18 jul. 2019.

GUILLOTE, do PSTU - Argentina. Argentina: não pagar a dívida externa ou mais miséria. LIT-QI, 2019, Buenos Aires, 2019, disponível em: $<$ https://litci.org/pt/mundo/america-latina/argentina/argentina-nao-pagar-a-dividaexterna-ou-mais-miseria/>. Acesso em: 18 jul. 2019.

IGLESIAS, Simone. MILLAN, Carolina. Moeda comum Brasil-Argentina? Uma miragem distante por enquanto. Exame, 2019, disponível em: $<$ https://exame.abril.com.br/economia/ moeda-comum-brasil-argentina-umamiragem-distante-por-enquanto/>. Acesso em: 18 jul. 2019.

LESSA, Antônio Carlos. A Construção da Europa. A Última Utopia das Relações Internacionais. Brasília: IBRI, 2003.

MINISTÉRIO DA ECONOMIA. Brasil e Argentina se reúnem para discutir comércio bilateral. Brasília: 1988, disponível em <http://www.economia.gov.br/noticias/2019/05/ 
brasil-e-argentina-se-reunem-para-discutir-comercio-bilateral>. Acesso em: 23 jul. 2019.

MINISTÉRIO DA FAZENDA. Política Fiscal. Tesouro Nacional, Brasília: 2019, disponível em <http://www.tesouro.fazenda.gov.br/sobre-politica-fiscal>. Acesso em: 18 jul. 2019.

NÓBREGA, Maílson da. Moeda única entre Brasil e Argentina é um delírio. Revista Veja, 2019, disponível em: <https://veja.abril.com.br/blog/mailson-da-nobrega/moedaunica-entre-brasil-e-argentina-e-um-delirio/>. Acesso em: 19 jul. 2019.

PECEQUILO, Cristina Soreanu. A União Europeia. Os desafios, a crise e o futuro da integração. 1. ed. Rio de Janeiro: Elsevier, 2014.

PECEQUILO, Cristina Soreanu. CARMO, Corival Alves do. O Brasil e a América do Sul - Relações Regionais e Globais. 1. ed. Rio de Janeiro: Alta Books, 2015.

PENA, Rodolfo F. Alves. Classificação dos blocos econômicos. Brasil Escola, 2019, disponível em: <https://brasilescola.uol.com.br/geografia/classificacao-dos-blocoseconomicos.htm>. Acesso em: 19 jul. 2019.

SANT'ANA, Jéssica. Peso real: as vantagens e riscos de uma moeda única entre Brasil e Argentina. Gazeta do Povo, 2019, disponível em: $<$ https://www.gazetadopovo.com.br/ republica/moeda-unica-brasil-argentinavantagens-riscos/>. Acesso em: 19 jul. 2019.

SEITENFUS, Ricardo A. S. A cooperação argentino-brasileira: significado e perspectivas. Lua Nova: Revista de Cultura e Política, n. 18, São Paulo, 1989, disponível em <http://www.scielo.br/scielo.php?script=sci_arttext\&pid=S010264451989000300008>. Acesso em: 19 jul. 2019.

SERVA, Fernanda Mesquita. DIAS, Jefferson Aparecido. Responsabilidade Social nas Instituições de Ensino Superior: entre o biopoder e a biopolítica. Revista Argumentum, V. 17, pp. 413-433, Jan.-Dez. Marília-SP: 2016. Disponível em: 
$<$ http://ojs.unimar.br/index.php/ revistaargumentum/article/view/319/64>. Acesso em: 22 jul. 2019.

SHALDERS, André. O que aconteceria se Brasil e Argentina adotassem o Peso Real como moeda única? BBC News Brasil, 2019, disponível em: <https://www.bbc.com/portuguese/brasil-48576812>. Acesso em: 22 jul. 2019.

SOUSA, Yvna. Copom mantém taxa básica de juros em 6,5\% ao ano. TV GloboBrasília, 2019, disponível em: <https://g1.globo.com/economia/noticia/2019/06/19/copom-mantem-taxa-basica-dejuros-em-65percent-ao-ano.ghtml>. Acesso em: 22 jul. 2019.

VILLAS BÔAS, Bruno. Brasil tem 13,4 milhões de desempregados no $1^{\circ}$ trimestre, indica IBGE. Valor Econômico, 2019, disponível em: $<$ https://www.valor.com.br/brasil/6232765/ brasil-tem-134-milhoes-dedesempregados-no-1-trimestre-indica-ibge>. Acesso em: 22 jul. 2019.

VISENTINI, Paulo Fagundes. A Política Externa do Regime Militar Brasileiro. 2. ed. Porto Alegre: Editora da UFGRS, 2011.

WOLFFENBÜTTEL, Andréa. O que é? União aduaneira. Revista IPEA, 2007, ano 4, ed.

em:

$<$ http://desafios.ipea.gov.br/index.php?option=com_content\&id= 2130 :catid $=28>$. Acesso em: 22 jul. 2019.

Enviado: Dezembro, 2019.

Aprovado: Janeiro, 2019. 